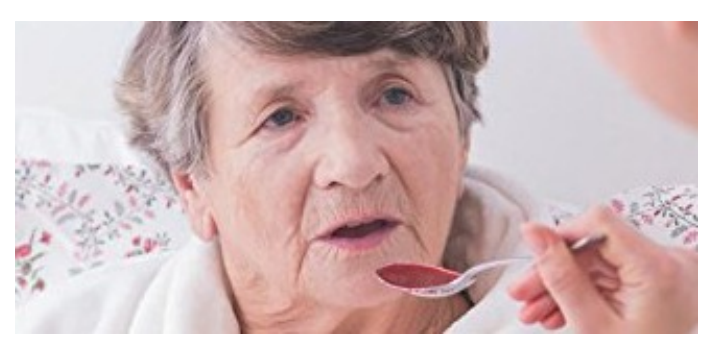

\title{
The refusal of food in the elderly patient: identification of the causes of rejection of the meal in senior age and hypotheses of intervention to prevent, treat and rehabilitate malnutrition
}

\author{
Giacomo Seccafien ${ }^{1}$
}

1 Centro Servizi Anziani di Chioggia - Felice Federico Casson

\section{Abstract}

Malnutrition can derive from causes that are independent of the patient's desire to feed themselves or which manifest themselves with the refusal of the meal; while for the former the strategies for solving and compensating the problem are more predictable, for the latter it is not always easy to have effective and prompt intervention procedures available.

The importance of a method that investigates the causes of food refusal and provides rehabilitative pathways to accepting the meal, designed to intervene on fasting in a structured way, lies in the timeliness and clarity of the roles.

I.R.M.I.E. (Investigation of the Rejection of Meal in the Institutional Elderly) analyzes the refusal of the meal and the consequent malnutrition linked to it, in the elderly subject institutionalized and not. It is thought of as a trace to identify the causes that lead the fasting patient to a condition of vital risk and to propose strategies of compensation and resolution to the problem. It is the premise of an individualized plan. It should be discussed as a team in the case and also given to the family member by the same or alternatively by a professional elected to the role, with a subsequent comparison. The planning of an intervention plan will follow, according to the procedures proposed in the manual that includes it, related to the identified 
causes, and of the resources exploitable in the service.

\section{Definitions}

Voice

Defined by Giacomo Seccafien

\section{EPIDEMIOLOGY}

The refusal of the elderly patient's meal: an important cause of death

Malnutrition has been calculated to cause death between $4.095 \%$ and $53.55 \%$ of the institutionalized elderly population, on average about one nursing home guest on 3. Although there is no statistic among the closely related causes of malnutrition to the refusal of the meal and not, this represents one of the most important reasons for death in geriatric community environments.

\section{MALNUT RITION IN THE ISTITUZIONALIZED ELDERY PATIENT}

A definition of "Malnutrition" is provided by the Italian Ministry of Health in the document ${ }^{[1]}$, which defines it as a condition of functional, structural alteration and development of the organism resulting from the imbalance between needs, income and utilization of nutrients such as to entail an excess of morbidity and mortality or an alteration of the quality of life. There are two major types of malnutrition: over and under. The latter, in particular, is not caused by a single factor but most of the time is due to multiple nutritional deficiencies, due to problems of chewing, swallowing, digestion, absorption, altered metabolism, loss of nutrients or increased needs. We recognize different forms of malnutrition by default, but later we will refer mainly to Protein-Energy Malnutrition (Protein Energy Malnutrition, PEM).

The guidelines continue specifying that malnutrition increases patient vulnerability, with greater morbidity and mortality. This situation is also responsible for the increase in complications, negatively affects the results of the therapies, reduces the immune response and predisposes to infections, delays scarring, compromises the function of organs and systems, reduces muscle mass and strength, induces harmful effects at the level psychic with depression and low interest in food. The literature reports that, in Europe, malnutrition is found with a frequency of $10-80 \%$ (on average $35 \%$ ) among the new admitted to hospital and that this condition worsens, in most cases, during the hospital stay itself . Elderly, cancer patients, surgical patients with org an and neurological insufficiency are among the categories most at risk. It is shown that over-eighty hospitalized patients are 5 times more likely to develop malnutrition than patients under 
the age of 50, and have less response to the treatment of malnutrition ${ }^{[2]}$. From this we can deduce that, besides lowering the quality of life and the effectiveness of the therapeutic / rehabilitative procedure, malnutrition can be an important cause of death but also a prognostic element to other causes of death. In fact: "the mortality statistics based on the only initial cause of death allow to observe only a part of a more complex morbid picture. This is true the more the mortality profile is characterized by long-term chronic diseases" [3].

\section{RELATIONSHIP BET WEEN REFUSAL OF THE MEAL, MALNUT RITION AND DEATH}

Based on the above, it shows a direct relationship between refusal of meal and death in elderly people institutionalized. You can ask yourself three basic questions to understand the importance of the problem:

- To what extent malnutrition causes of death in the geriatric community setting?

- What percentage of seniors in nursing homes is malnourished and / or at risk of malnutrition?

- In what amounts malnutrition stems from the refusal of the meal? You beg in by answering the first question.

The importance of malnutrition by defect is relevant: in elderly malnourished mortality at 14 months was $63 \%$, compared with $9 \%$ in normonutritoned people ${ }^{[4]}$.

Malnutrition is associated with decreased nutrient intake (most common mode in the elderly) is recorded in different percentages depending on your frame of reference:

- $\quad 1-15 \%$ of outpatients;

- 25-60\% of institutionalized subjects;

- $\quad 35-65 \%$ of hospitalized patients. $\quad{ }^{[5]}$ (Bell, 2015; Arvanitakis, 2009; Wirth, 2015; Council of Europe, 2009)

Another statistic is provided in "Studio Pimai - Italy (Project: Iatrogenic malnutrition in Italy) of Lucchin et al, 2009 - Prevalence of Malnutrition in nursing homes ${ }^{[6]}$ ) ". On a sample of 67 regional residences ( $23 \%$ of T uscan structures), they were reported in 2800 assisted at high risk of malnutrition, equal to $21.5 \%$ of the total and $32.7 \%$ according to a second computing strategy. The article mentioned the Fallani doctor, which participates with the previous data, so far as it is updated at our disposal to answer the second question, goes on to specify that: "In RSA malnutrition is a sometimes extremely frequent condition; the literature reports percentages between $6.5 \%$ and $85 \%$, calculated using different methodologies or indicators.".

So, if literature can bring back the $85 \%$ of guests malnourished in social and health 
facilities, and it was said that in elderly malnourished sub mortality that is $63 \%$ at 14 months, in the worst malnutrition is the cause of $53,55 \%$ of deaths of institutionalized elderly: more than half. Regarding the correlation between rejection of the meal and other causes to it divorced that lead to malnutrition, there are still no statistics in the literature that can give an accurate measurement. Nevertheless, on an empirical level, you can understand that the refusal of the meal is due to an important part of the causes of malnutrition identified in research and epidemiological studies related to it, and that is what we are going to deal with in the next chapter.

\section{THE REFUSAL OF THE MEAL: AN UNCERTAIN ROLE OF INTERVENTION AND THE IMPORT ANCE OF A METHOD}

When a guest refuses a meal at a nursing home, several actions may be followed by the event. Surely the fact is noted, as it is common practice (and legally obligatory) to keep diaries and reports on each patient by the staff members, each in their own area of competence respectively. The single episode of rejection of the meal, in the absence of a guideline, could be overlooked and considered a moment of fasting "granted" to the person, underestimating that inappetence can be a symptom or manifestation of an important discomfort and can have dangerous consequences. However, if repeated over time, fasting is unlikely to be considered a problem, as it makes it difficult to guarantee the adequate nutritional intake for the refusing guest, up to malnutrition. The first indication is assumed to start in most cases by those who assist the patient more closely and more frequently over time; the socio-health worker, who except in special cases administers and monitors the meals of each patient, highlights the difficulty in feeding the patient, who through the referent / coordinator is brought to the attention of the team.

The composition of the team depends on the regional legislation, but generally the figures involved in the health-care-rehabilitation in the nursing home are: doctor, nurse responsible health, coordinator Oss of the nucleus, social worker, psychologist, physiotherapist, speech therapist and professional educator . The refusal of the meal, although it may be said as a dangerous alarm bell, will surely be perceived as an important problem when it involves malnutrition, putting the guest's life at risk. At that moment, there is no clarity on which professional figure has the task of taking charge of investigating the issue and proposing solutions. After a brainstorming, the hypotheses of intervention can be very many: the doctor, visiting the patient, can exclude drug-related side effects and the presence of discomforts that imply lack of appetite; the psychology service will be able to verify if there is depression with apathy towards the meal, or if present dementia, how much it is going to affect the ability / desire / rituality to feed 
itself; the speech therapist can evaluate hypotheses of dysphagia and resort to a dietician to draw up a diet if there is a quantity of nutrients actually taken and yet if there are sores in the mouth and dental congruence, and so on. If the problem does not resolve, the only solution that will be proposed by the team to the family will be that of an artificial nutrition.

In terms of time, the weight loss of a fasting elderly person can be sudden and rapid: if he is immobilized, the resting compacasa of decubitus injuries in the absence of sufficient caloric and water intake can go down even under 36 hours, independently from posture and medication and other attentions to prevent them. In the walking guest, the fact of not eating will weaken, weaken it and reduce its autonomy, and so saying can be reported other dozens of prognosis in which it is understandable that the refusal of the meal leads to accelerate the decay and trigger a vicious circle in the what is the growing difficulty of making it reversible, due to the accentuation of problems and problems related to it.

The importance of a method lies in the timeliness and clarity of the roles, which investigates the causes of food rejection ad-personam and proposes rehabilitative paths to the acceptance of the meal, designed to intervene on fasting in a structured way. Even if you are spending a lot of attention on how to identify and intervene on the problem, we must not neglect the aspect of prevention. "To screen or not to screen for adult malnutrition" is the title of an article by Marinos Elia ${ }^{[7]}$ published in 2005 which states that the inability to recognize and treat malnutrition is unacceptable, especially where it is more frequent, therefore it is recommended the routine use of simple screening tools for malnutrition or nutritional risk. Elia also concludes by stating that in every place of care and assistance transparent policies should be adopted for the use of nutritional screening, policies that should vary according to the setting, available resources and characteristics of the subjects to be evaluated. Early identification of individuals with nutritional risk through screening tools, followed by adequate nutritional interventions, can in fact contribute to preserving muscle function, preventing or at least restraining sarcopenia and therefore maintaining physical self-sufficiency, quality of life, and the increase in the probability of survival.

\section{CAUSES OF MALNUTRITION}

Malnutrition in the institutionalized elderly: a consequence and / or manifestation also of the refusal of the meal

Malnutrition can derive from causes that are independent of the patient's desire to feed themselves or which manifest themselves with the refusal of the meal; while for the former the strategies for solving and compensating the problem are more predictable, 
for the latter it is not always easy to have effective and prompt intervention procedures available.

\section{CAUSES OF MALNUT RITION RET URNABLE OR LESS THAN THE MEAL'S}

\section{REFUSAL}

In the scientific literature, both historically and internationally, there is still no homogeneous and definitive cataloging that collects all possible causes of malnutrition. The malnutrition itself does not have as its sole cause those that derive or that manifest themselves with a refusal of the meal. If we mean malnutrition that has arisen or has been treated in a nursing home as obstinate, chronic, continuous and / or non-reversible weight loss by the health care work team, we must distinguish the causes in two categories:

- $\quad$ Causes that are manifested in avulsed way the willingness and host expressiveness, which is unable to eat or whose weight loss is independent of the amount of taken meal;

- $\quad$ Causes due to refusal of the meal and / or arising from the rejection of the meal itself.

The "National guidelines for hospital food and assistance"[8] provided by the Ministry of Health and reported in the chapter, indicate as factors that contribute to the genesis of malnutrition in the elderly:

"Habits and inadequate or insufficient food consumption / Decreased / restrictive dietary requirements or inadequate / drug-nutrient interaction / Change in energy needs and nutrient / edentulous and mismanagement of the prosthesis / nausea-vomiting, malabsorption, diarrhea lasted / disorders chronic / Confusion, depression, dementia / functional deficits or motor or sensory / dysphagia / Parkinson's and other neurological disorders / cultural level / Poverty / Institutionalization / isolation, inability to obtain and / or prepare food / poor service or unprofessional at meals. "

A nutritional, clinical, neuropsychiatric and social, all these points describe possible causes of fasting and lack of appetite, that may manifest themselves as an inability to feed and as a rejection of the meal.

The study, "Epidemiology of malnutrition in the elderly" [9] (by Dr. Alessandra Coin Geriatric Clinic - University of Padua, presented the 8th multi-professional course of Nursing Florence, November 29 to 1 December 2007) draws conclusions than analyzed all nursing homes present in Helsinki, Finland. By 2114 elderly malnourished 29\% turned out, those at risk 60\%, and causes reported by Suomonen M. et al, (European Journal of Clinical Nutrition $2005^{[10]}$ ) were identified as: 
"No self-sufficiency / Dementia / Outcomes of stroke / Constipation / swallowing disorders / Eat only half a meal for appetite / welfare deficiencies such as lack of snack and infrequent weight control."

"The assistance picky guest" (the table WORKING ASL BRESCIA - RESPONSIBLE FOR HEALTH OF RSA / RSD PROT OCOL POWER in RSA / RSD - Protocol ${ }^{[11]}$ ), is the case with the same key reading but by slightly alternative views previous article, and describe it as follows.

A situation of loss of appetite (anorexia and) is common among the elderly, particularly if hospitalized in a RSA. In many situations it is secondary to physical illness (gastrointestinal tract but also heart, lung, kidney, etc.), To mental illnesses (depression, dementia), the use of drugs that suppress the appetite, to ' combined effect of aging and disease. There are however a number of causes that can be corrected and whose early detection can help the host to maintain or recover an adequate dietary intake; in particular, it is always necessary to check:

"The condition of the oral cavity: edentulism (lack of teeth), presence of dental roots causing irritation of the gums, malfunctioning prostheses, poor hygiene of the teeth and mouth, oral infections / intolerance for some foods / constipation (constipation) obstinate / the presence of fever, dehydration, confusion (delirium). In other cases we are, in fact, faced with an inability for the person to take food properly due to: reduced manual dexterity; vision impairment; overall reduction in vision, but also inability to discriminate different shades of the same color (it may be difficult for a demented person to identify white mash or stracchino on a white plate); inability to "see" food placed in one half of the dish as a consequence of a brain injury; apraxia: inability to organize a series of movements in a complex action, such as picking up a cutlery, collecting food and bringing it to the mouth (in this case it may be useful to "guide" the beginning of the movements); agnosia: incapacity for the person (mostly affected by dementia) to understand the situation and the meaning and the use, for example, of a cutlery (also in this case it may be helpful to help the person to start the action); incorrect posture, which makes it more difficult to autonomously take food and / or compromises swallowing. In other cases, finally, insufficient food intake is linked to organizational problems such as: meal times too close; too little time dedicated to the meal and in particular to the meal; the confusion in the dining room; the presence at the same table of guests with incompatible characteristics ".

What is researched until now (the related citations are only a few choices from an investigation on the subject much broader) identify malnutrition's reasons as a social nature, environmental, psychological, sanitary-pathological (organic, morphological or motor and pharmacological treatment), neurological (degenerative or stroke) and 
welfare.

From the bibliog raphy consulted on the issue you are able to specify 9 of malnutrition causes detached from rejection, and argued listed in the section to follow. Those rather closely related to the rejection of meal are forty and that are the result of this study.

\section{THE CAUSES OF MALNUT RITION THAT ARE NOT CORRELATED WITH REFUSAL OF THE MEAL}

A patient can develop malnutrition for reasons beyond his will to eat or not: in fact, what takes the meal until the satiety may be insufficient because disease and current therapies cause a sudden weight loss or failure to absorb nutrients, or because his (in) mobility makes afagico, or little assistance in the context of limited autonomy, or even as a state of drowsiness very important over time does not allow him sufficient supervision to consume the food.

From what has been collected in the scientific literature, the causes of malnutrition uprooted by a refusal which are the following are divided into expenses resulting from absorption deficit, a neuro-motor disorders, for integ rity of the structures and level of assistance:

1. Oncological or degenerative diseases of the apparatuses

Tumors and degenerative diseases may require greater nutritional intake while reducing the appetence of the patient.

2. Dysfunctions and organic removals

The dysfunction of the organs which take part in the digestion (or their removal as in gastrectomy) compromises the proper absorption of nutrients, with a consequent reduction in the quantity of calories.

3. Interactions between medications and nutrients

Some medications can reduce or even inhibit the absorption of specific nutrients.

Chronic Diarrhea and vomiting

They can represent the expulsion of undigested food material or stimulate secretions to be expelled, malabsorption and debilitation.

Stroke, outcomes of intervention and / or diseases that make serious appearance morpho-physiological locomotor

These events can lead to lack autonomy, compensated in assistance, but especially important because the dysphagia patient requires careful evaluation and rehabilitation to have a real prognosis for recovery and the risk of suffocation. The latter paintings relate mainly to immobility or demolition of part of the respiratory apparatus.

Drowsiness as a reaction to medications

Side effects of certain drugs or excess dosage of the same (especially, the elderly, those 
that serve to act on agitation and behavioral disorder) can cause drowsiness, namely reduction of supervision. In this case, the guest does not feed as incapable of sustaining attention; the power supply itself can be dangerous and invalidated in dysphagia.

Advanced stage of dementia or neuro / degenerative locomotor diseases or vegetative state

The absence of supervision does not allow power to OS. The same applies to the final stages of some degenerative diseases that lead to important stiffness of the swallowing structures (eg. Parkinson, Korea ....).

Frequent withdrawals, fast to exams

Malnutrition can result from the loss of nutrients linked to levies or forced fasts for clinical examinations that require it, whether they have an extremely high frequency and debilitating.

Lack of assistance or pre-existing malnutrition entrance

Malnutrition can be observed as a framework that already exists at the entrance of the host, therefore, for unknown reasons or due to lack of previous interventions to RSA context. Where then the autonomy to be very low, the power must be delayed (eg. Gastrectomizzati) and / or if the meal times are long, the assistance deficiency can lead to an insufficient amount of food intake.

Despite the reasons that follow, related and / or manifested with the refusal of the meal, the prognosis and the possible resolution of the problems described here it is much more intuitive. You can resort to healthcare pathways such as:

Choice of specific supplements and a high-calorie diet ad personam, when the appetence is low and you need a higher nutritional value, as a result of the higher need for calorie intake dictated by the disease;

To reduce the nutrient malabsorption, diarrhea and vomiting, drowsiness and increase alertness, wellbeing and harbored a desire, it is appropriate to establish a drug treatment plan, or revisit the same if the causes of malnutrition are secondary to side effects of the same treatment in progress ;

When the dysphagia is so serious as to make possible a rehabilitative treatment, compensatory to new strategies, caloric and water intake may be introduced into the body with artificial feeding (which bypasses the respiratory apparatus). We evaluate routes of parenteral and enteral nutrition (moisturizing drip, Central Venous Catheter, PICC, Midline, SNG, PEG, PEJ etc.) In the cases of secondary aphagia for example in oncological diseases, interventions demolition respiratory apparatus, a vegetative state, was important in non-supervisory time, motor neuro-degenerative diseases that cause rigidity of swallowing structures (eg. Parkinson's disease) or stroke that lead to irreversible loss of control of swallowing or more specifically of the structures related to 
the glottis plane;

Provide more support, even with the help of assistants and caregivers, when the host needs more time to enjoy your meal (lack of partial or total autonomy, general slowness or acceptance of a dish but that requires chewing higher), or needs frequent meals and deferred or at different times from those canonical (eg if you have exams in meal times).

\section{TOGET HER INTERSECTION}

Given the complexity of the issue, will be reported between the two lists respective descriptions with an excursus on the 'between intersection"; it represents the list of the causes of malnutrition "hybrid", that are manifested in the refusal albeit from a problem previously treated in the last part of this chapter.

- Health-pathological level:

The malabsorption of nutrients related to impairment of digestive organs, may cause weight loss and malnutrition not only directly since there is a sufficient caloric intake, but also due to a secondary consequence, represented a no-hungry condition for physical discomfort. As we will see in particular in cases of treatments, once it resolved the cause of the illness there is good chance that the hunger reappear. In this case, the part evaluative of this manual may serve as a starting point to suggest greater attention in the patient's screening towards pathological inferences such as: compression for ulcers organs, air and masses, pain during chewing, swallowing and / or digestion and finally pain distal undervalued or not expressed (pressure ulcers, hemorrhoids, diverticulosis, more suffering etc.). The same diarrhea, vomiting and constipation not only affect food absorption, but they create poor appetite due to pain and quite uncomfortable sense that they create, leading the host to reject the meal and hydration, into a spiral where over not to digest what has already assumed, it does not integrate as lost or necessary.

Therapeutic drug level:

The damage that can cause a drug at the wrong dosage is due to malnutrition in possible side effects not only for interaction with the assimilation / metabolism and drowsiness / lowering of vigilance. It can interfere behavioral bringing out atypical emotional aspects compared to historic patient in which it could refuse the food. In these cases, it may have been stimulated aggression, direct or secondary disorientation at times dementing (vascular in particular) and confabulation. In addition, the drug can lead all'inappetenza if inhibits hunger or taste perception.

- Grade of care assistance:

As already said, when the needs of a customer requiring a higher level of care on powerup, it is necessary to comply with them. If assistance does not fulfill these needs, besides the fact that caloric intake is insufficient, there is a risk of developing mortification, 
mistrust and the host provocation. For example, the sense of satiety and fullness faster, fatigue and physical sluggishness in chewing and residual autonomy, meal times inadequate or the monotony of the diet need to spend more time on care of the person or to split the meal at different times of the day, or even propose a greater variety of dishes, otherwise presented.

\section{THE 40 CAUSES OF REFUSAL OF THE MEAL}

The refusal of food in the institutionalized elderly can be a consequence or manifestation of various events. In this study, forty causes were identified, whose complete cataloging (even if this is not yet subject to formal validation) is first and only in the literature, developed by questionnaire and manual of treatment hypotheses. The causes that lead to the refusal of food or that occur in this event with regard to the institutionalized elderly, are addressed only to fasting patients with stretches of vigilance. As explained in the previous paragraphs, it would not be permissible to define those who are vegetative, coma and stupefied, or who accept food but whose absorption is affected by pathological, iatrogenic or morphological causes.

The list was obtained by the writer after careful analysis of the literature itself, but above all through interviews and reflections carried out from October 2014 until September 2017 at 10 geriatric residential facilities in the North-East of Italy.

The nursing homes in which the survey was carried out during the activity as a speech therapist were: "F.F.Casson" of Sottomarina in Chioggia and "C.D. Muneghelle", "Korian" Service Center Ca 'Vio of Cavallino-Treporti, IRE in "Zitelle" of Giudecca in Venice and "San Lorenzo" of Venice," Istituto Pio X "of Cordignano, OSMC in "Centro Nazaret" of Zelarino in Mestre-Venice and "Santa Maria del Mare" in Pellestrina in Venice, "Istituto Carlo Steeb" in Lido di Venezia (Venice) and "Residenza Gruaro".

The research work ${ }^{[12]}$ was embellished by personal experiences or provided by those who wanted to collaborate in the project, from home treatments in collaboration with "PrivatAssistenza" of Jesolo, from the availability in nursing homes mentioned to access departments specific in dementia as the S.a.p.a. but also trasvecasa of rest like Psychiatric Points, Hospice, C.Sla and HIV, and finally from the precious experiences with disability at "Bellinato-Zorzetto" and "Amici Insieme" of Mestre and "Ass. Our Family "of Padua.

By limiting the observed sample to the geriatric field, the 3-year observational training always involved at least 2 facilities simultaneously for no less than 6 months each, with an average of 102 guests per location. In total, more than 1150 guests were assessed (number accentuated compared to the expected average due to deaths and transfers). Already in January 2016 the consultation of the scientific literature had been completed, 
and with the cases studied in this experience a first list was drawn up showing 26 causes of rejection of the meal and 19 hypotheses of resolution. Thus 219 voluntary interviews were carried out by health personnel in which they asked themselves what other causes of rejection of the meal were found in their professional experience. In August 2017, for over 50 days and as many new interviews, the considerations collected were redundant in a new sample and no additions appeared.

The elder, therefore, can refuse the meal because:

1. The patient eats less with age

Senility leads to inappetence and imbalance of the organic picture (examples of imbalances that reduce hunger are zinc deficiency and reduced production of hormones processed by corticosurrene).

2. The patient has a sense of satiety and fullness faster Because of age, greater digestion time or fasting that reduces the volume of the stomach, the elderly can feel full while not having taken a sufficient caloric intake.

3. They are missing that "fatigue" and that movement that are "hungry" The patient is not appetite because it reduces his movement and physical consumption. 4. The patient has difficulty perceiving the appetite The patient has never been a "glutton": he has a history in which he has not been accustomed to striving to consume a fair portion of food, tending to weight loss and defect in quantities in an "innate" way, due to causes not related to aspects related to old age.

5. The patient does not accept the structure and condition of institutionalized The patient may not accept himself in his condition of necessary assistance. He can refuse the meal as a form of provocation and protest, but also as a consequence of mortification and loss of self-esteem, as well as feeling "prisoner" in a place and in a social-health condition that he is not congenial to.

6. The patient has no confidence in the operator (especially if the elderly person presents ipovisus)

The elderly person may not feel comfortable in being looked after, especially if he is visually impaired and therefore less aware of the modalities of contact and of the carrying out of the actions of the caregiver towards himself; he may develop rejection at the entrance, if not autonomous, if that moment is not completely serene.

7. The patient refuses food as a reflection of disapproval from care-givers The patient can become a transference of loved ones, and if they show distrust, anger, sadness or anything else towards the community structure, and these emotions can be reflected on his behavior. 
8. The meal times are insufficient compared to the needs

As mentioned, where more time is required for meal consumption and assistance is not sufficient to compensate for the problem, the patient can refuse the meal due to a sense of defeat, lack of self-esteem or protest.

9. The patient reports to perceive odor and / or have unpleasant vision during the meal The elderly may not feel comfortable in the community environment and develop lack of appetite for unpleasant stimuli; when they are perceived in the dining room, they penalize in an important way the acceptance and consumption of what is proposed.

10. The diet is monotonous

The lack of a good presentation and the variety of foods can cause them to be rejected. 11. The patient has sensorial olfactory / gustatory disability: he feels less the flavors The inability to feel the flavors is going to undermine the pleasure of the meal.

12. The patient has health food limitations: diabetes, allergies, treatment diarrhea, diverticula etc.

The dietary limitations related to the treatment of a disease or a disorder can make the meal less tasty or exclude dishes judged important and particularly pleasing to the patient, who may perceive the food tasteless or develop waste as provocation.

13. The dental prosthesis is incongruent or is edentulous and the consistency is not chewable

The refusal may derive from the difficulty or even the inability to chew food, which can mortify and lead to "surrender" to the consumption of the meal.

14. The taste and / or consistency of food has varied and is perceived as disgusting The patient may not like the dishes, perhaps used to experience other flavors, or when a variation in the consistency of liquids / solids has been necessary, it may be unpleasant or even lead to rejection as provocation.

15. Mastication and swallowing require physical effort, the patient is lazy and / or has reduced autonomy

Although respecting times, physical fatigue in praxis and oral acts can create a negative reinforcement of food, reducing pleasure and hedonism.

16. The patient presents pain during chewing, swallowing and / or digestion Cause of rejection towards the meal can derive from a pain that appears directly in the alimentary act, therefore during the chewing (involving the oral cavity), swallowing (high respiratory tract) and digestion.

17. The patient has distal pain (bedsores, other sufferings, etc.)

Also a pain of another tissue removed from the role of food is a cause of distraction and lack of appetite, as it is perceived as a more urgent discomfort to be solved compared to hunger. 
18. The patient is affected by the chronicity of org anic discomforts (constipation, nausea, diarrhea, infections, etc.)

The feeling of crushing of the intestine, diaphragm and stomach can result from constipation which makes the bowels full; even the chronicity of discomfort can lead to an "a priori" refusal of the meal.

19. The patient has a compromise / compression of organs (ulcers, air, masses, etc.) A feeling of crushing and malaise that deceptively gives a sense of satiety can also derive from the compromise of the digestive organs due to inflammation, meteorism and neoformations.

20. The patient has a feeling of crushing / incoordination due to restraint Physical restraint can create a crush on the abdomen (intestine, diaphragm, stomach) creating the illusion of a fullness, until it becomes a real obstacle to digestion.

21. The patient has communicative deficits (aphasia, dysphonia, dysarthria, hearing disability)

The inability to communicate one's needs, as well as being mortifying, can be a direct cause of inappetence or secondary to the impossibility of communicating a discomfort.

22. The patient suffers from hypothetical side effects of drug therapy (eg Sleepiness) Drug treatment can cause a change in the patient's behavior, which may become unable to feed due to fatigue or drowsiness even if he renounces the task, or bring out a refusal related to cognitive impairment.

23. The patient is affected by disorientation of the low blood pressure lift or a cause of paroxysmal positional vertigo

If a postural passage is necessary immediately before the meal, vertigo and disorientation of various kinds (spatial or motor incoordination) may occur, compromising the patient's serenity.

24. The patient has orientation problems related to an environment and to the environment

Spatial disorientation can lead the elderly to get lost and confused: a community structure (not only immediately after entry) is a foreign environment, and the patient can feel uncomfortable eating the meal, avoiding or interrupting it, as it does not recognize the new setting as a domestic.

25. The patient has serious temporal disorientation

The elderly with significant temporal disorientation can "live in a past time", refusing food to supply it with hypothetical young children. Even the doll of "Doll Therapy" can be confused for them.

26. The patient does not recognize food as subsistence due to dementia The patient may forget the function of food as sustenance due to cog nitive impairment, 
and the loss of short-term memory can make him lose the task during the act of eating, or make him forget whether he ate or not and how long perpetuate a fast.

27. The patient forgets the bolus in the mouth due to dementia

Short-term memory loss can also make the patient forget to have a bolus in the mouth as soon as it is introduced, resulting in an apparent refusal (consequences may be rejection or passivity).

28. The patient presents hallucinations that disturb him (he pursues, he feels bodies in his mouth, etc.)

During the meal, the elderly person may be affected by hallucinations (which may involve all 5 senses, secondarily to cognitive, psychiatric and / or iatrogenic disorders) and therefore may be distracted and inappetent. A particular delirium can make him believe that food is poisoned and harmful, creating a very strong waste.

29. The patient presents childish regression: he refuses out of spite or as a child's scheme

Cognitive impairment can bring out patterns of rejection similar to child behavior.

30. The patient has a constant urge to go to the toilet but he is unable to do it by himself The feeling of having to discharge (evacuation or urination), real or secondary to a moment of cognitive decompensation linked perhaps to a dementia base, certainly distracts from hunger, since the problem is naturally perceived as a more important need.

31. The patient presents wandering, has difficulty staying still during the meal The necessity of perpetrating the continuous motion without a purpose, of a demented with wandering, is primary with respect to hunger and makes the staticity and concentration required in taking the meal difficult, which can be refused.

32. The patient is afraid of suffocating after an episode of negative reinforcement Following an episode of aspiration or penetration of the bolus in the airways, the patient may be frightened (of the sensation and the discomfort that can be followed, such as apnea, fever and cough) and refuse the meal for fear that it may happen again.

33. The patient has sadness for the loss of the home and rhythms and habits are consolidated in it

The bad mood generated by the abandonment of one's own home can cause inappetence and apathy towards the pleasure of feeding oneself, until reaching the depression. Also the variation of one's own rhythms and habits, the decrease of activity and the variation of the times in which the patient usually consume the food, can be a cause of rejection.

34. The patient has lost self-esteem: he is mortified in being fed The patient may not accept the reduction of his / her autonomy, feel downcast and 
humiliated until he / she wants to avoid, through opposition and passivity, the situations in which he / she perceives this sensation most.

35. Depression and stressful events have meant apathy behavior towards meal pleasure Aspects of depression are the apathy and loss of pleasure, even inherently to nutrition. Depression can also be transitory as a physiological phase of mourning of various kinds, not only due to the death of a loved one. Finally, some other stressful events not previously mentioned may cause loss of appetite.

36. The patient chosen to "reject life" wants to speed up the departure Although lexically it would not be correct to speak of "suicide" or "euthanasia", the refusal of the meal may be for the patient a conscious choice to decide to die.

37. Previous or current anorexia nervosa or psychiatric illness is found Malnutrition due to rejection of the meal can be dictated by some disturbances not previously mentioned of a psychiatric nature or anorexia nervosa, in which (not due to dementia) the patient is afraid of getting fat and appearing "imperfect". Usually this behavior has a history and re-emerges after having already appeared in the experience of the person in question.

38. The patient presents drug abstinence or previous dependence on psychotropic substances and alcohol

Substances such as topiramate, amphetamine, exenatide, methylphenidate and methamphetamine reduce appetite both during consumption and during withdrawal. The same signs of abstinence can be found for stimulants such as coffee, nicotine and cocaine, as well as during detoxification from any form of addiction (alcohol in the first place). Finally, food may not be satisfying in reducing the consumption of pharmacological therapies linked to some antidepressants or clearly after the sudden suspension of essences that increase appetite.

39. The patient is suffering from "Node in the throat" or vomiting due to psychogenic esophageal dysphagia

Esophageal dysphagia in the elderly, if not secondary to mechanical obstructions, ongoing pathology of the digestive organs or iatrogenic reaction, can be compared to a true form of bulimia and has been defined in some Italian articles in 2017 as "inexplicable", probably a psychogenic basis.

40. The patient carries PEG / SNG but can not assimilate what is expected in the stomach Artificial nutrition that reaches the digestive tract bypassing the respiratory system may not be assimilated for various reasons often linked to the enteral medium or to the state of the organ that receives it. In reality, bulimia-like rejection forms without explicit causes are observable, which can be traced back to an anxiety state similarly to the psychogenic type of esophageal dysphagia described above. 
Now concluded the process of giving awareness on what is the refusal of the meal, the importance of the problem and the research carried out to catalog and disting uish the causes, we report the questionnaire "I.R.M.I.E." (Rejection of Meal Rejection in the Institutionalized Elderly ), an instrument for the health, welfare and rehabilitation team in nursing homes.

(c) dr. Giacomo Seccafien

\section{I.R.M.I.E.}

Investigation of the refusal of the meal in the institutionalized elderly

I.R.M.I.E. Test analyzes the refusal of the meal and the consequent malnutrition linked to it, in the elderly subject institutionalized and not. It is thought of as a trace to identify the causes that lead the fasting patient to a condition of vital risk, and to propose strategies of compensation and resolution to the problem. It is the premise of an individualized plan. It should be discussed as a team in the case and also given to the family member by the same or alternatively by a professional elected to the role, with subsequent comparison. The planning of an intervention plan will follow, according to the procedures proposed in the manual that includes it, related to the identified causes, and of the resources exploitable in the service.

1. The patient eats less with age

2. The patient has a sense of satiety and fullnessfaster

3. They are missing that "fatigue" and that movement

4. The patient has difficulty perceiving the appetite

5. The patient does not accept the structure and condition of institutionalized

6. The patient has no confidence in the operator (especially if the patient presents ipovisus)

7. The patient refuses food as a reflection of disapproval from care-givers

8. The meal times are insufficient compared to the needs

9. The patient reports to perceive odor and / or have unpleasant vision during the meal

10. The diet is monotonous

11. The patient has sensorial olfactory / gustatory disability: he feels less the flavors

12. The patient has health food limitations: diabetes, allergies, diverticula etc.

13. The dental prosthesis is incongruent or is edentulous and the consistency is not chewable

14. The taste and / or consistency of food has varied and is perceived as disgusting

15. Mastication and swallowing require physical effort, the patient is lazy or has reduced 
autonomy

16. The patient presents pain during chewing, swallowing and / or digestion

17. The patient has distal pain (bedsores, other sufferings, etc.)

18. The patient is affected by the chronicity of organic discomforts (constipation, diarrhea, infections...)

19. The patient has a compromise / compression of organs (ulcers, air, masses, etc.)

20. The patient has a feeling of crushing / incoordination due to restraint

21. The patient has communicative deficits (aphasia, dysphonia, dysarthria, hearing disability)

22. The patient suffers from hypothetical side effects of drug therapy (eg Sleepiness)

23. The patient is affected by disorientation of the low blood pressure lift or a cause of vertigo

24. The patient has orientation problems related to an environment and to the environment

25. The patient has serious serious temporal orientation

26. The patient does not recognize food as subsistence due to dementia

27. The patient forgets the bolus in the mouth due to dementia

28. The patient presents hallucinations that disturb him (he pursues, he feels bodies in his mouth, etc.)

29. The patient presents childish regression: he refuses out of spite or as a child's scheme

30. The patient has a constant urge to go to the toilet but he is unable to do it by himself

31. The patient presents wandering, has difficulty staying still during the meal

32. The patient is afraid of suffocating after an episode of negative reinforcement

33. The patient has sadness for the loss of the home and rhythms and habits are consolidated in it

34. The patient has lost self-esteem: he is mortified in being fed

35. Depression and stressful events have meant apathy behavior towards meal pleasure

36. The patient chosen to "reject life" wants to speed up the departure

37. Previous or current anorexia nervosa or psychiatric illness is found

38. The patient presents drug abstinence or previous dependence on psychotropic substances and alcohol

39. The patient is suffering from "Node in the throat" or vomiting due to psychogenic esophageal dysphagia 
40. The patient carries PEG / SNG but cannot assimilate what is expected in the stomach

NOTE: the questionnaire is aimed only at fasting patients with stretches of vigilance (not suitable for subjects in a vegetative / coma / stuporous state, or who accept food but whose absorption is affected by pathological, iatrogenic or surgical-morphological causes).

\title{
Hypotheses of intervention to prevent, treat and rehabilitate malnutrition
}

\author{
Cause of the I.R.M.I.E. Test $n^{\circ} 01$
}

THE PATIENT EATS LESS WITH THE ADVANCE OF THE AGE FOR PHYSIOLOGICAL DECAY

In the elderly, inappetence can be a physiological event linked to general decay, and even without other complications it can lead to rejection of the meal until malnutrition. The most specific causes around which it is possible to study drug therapy are due to zinc deficiency, reduction of the hormone levels developed by corticosurge, the correct function of the hypothalamus, the excessive activity of leptin and insulin, the postproduction of anorectic hormones, slowed gastric motility and inhibition of nerve centers of hunger and / or pleasure neurons, creating a condition of 'anorexia of aging'. In the receptive patient it is possible to establish a collaboration through the counseling with the aim to undertake a path stimulating the appetence; the proposed activities can be the offer of small meals spread out in the day and the preparation of a space used as a "T ea Room" as a hedonistic moment for hydration. The most caloric foods will always be chosen and it is advisable to use supplements, always in the consistency of the clinical picture and involving the family members. Cooking activities where the guest prepares his own food and olfactory stimulation in which he describes what he perceives to be less effective but the same can be proposed. In the patient who does not communicate effectively, the approach becomes much more complex than the analogue that can understand the messages and express their needs. In this regard, we invite you to consider the strategy of stimulation of mirror neurons by imitation: this procedure is done by sharing the meal time with the care-givers in a very quiet setting and at least polluted, where all participants will take the dishes one at a time. in the same form, quantity, appearance and posture, mutually clearly visible. This measure aims to make the patient imitate the action he sees, and therefore to consume the meal "by reflection". 
Cause of the I.R.M.I.E. Test $n^{\circ} 02$

THE PATIENT PRESENTS SENSE OF SAZIETY AND FASTER FULLNESS

In the elderly, which in itself tends to reduce the amount of meal taken, inappetence can result from a sense of satiety and rapid fullness, dictated by previous eating habits and by reducing the volume of the stomach. In the receptive patient it is possible to establish a collaboration with the aim of creating moments in which the act of "tasting" and consuming a dish is practically a pleasure that the inappetent self-imposes irrespective of the sense of hunger. The proposed activities can be gastronomic, in which the guest prepares his own food, of olfactory stimulation where he describes and guesses what he perceives (for the purpose of reactivating the appetite and the interest in food), as well as the offer small meals spread out in the day with the preparation of a space used as a "tea room" as a hedonistic moment for hydration. The most caloric foods will always be chosen and the use of supplements is recommended, in the consistency of the clinical picture and involving the family members. In the patient who does not communicate effectively, the approach becomes much more complex than the analogue that can understand the messages and express their needs. In this regard, we invite you to consider the strategy of stimulation of mirror neurons by imitation: this procedure is done by sharing the meal time with the care-givers in a very quiet setting and at least polluted, where all participants will take the dishes one at a time. in the same form, quantity, appearance and posture, mutually clearly visible. This measure aims to make the patient imitate the action he sees, and therefore to take the meal "by reflection". Also in this case, due to the rapid sense of fullness, a specific diet should be chosen with the support of the supplements so that the reduced meal is sufficiently nutritious.

Cause of the I.R.M.I.E. Test $n^{\circ} 03$

DISCOVER THE "FATIGUE" AND THE "MOVEMENT" THAT PROVOKES “HANGER" In the elderly the refusal of the meal may be secondary to lack of appetite deriving from the lack of fatigue and movement, which also compromises the quality of his life in the community structure. As a solution and prevention to the problem, we recommend occupational activities that acceptably affect the patient, especially if manual, such as the manipulation of objects suitable for the construction of something tang ible and rewarding, with the awareness that it can not be endangered. To satisfy the patient, he can be elected to a role within the structure that increases his / her self-esteem (ie, the porter) and the same is valid with respect to food (eg food taster). With dual values of both employment and stimulation of appetite we can also propose activities of construction and daily cultivation of a vegetable garden, with the involvement of caregivers. The manual activity that acts as tactile sensory stimulation and moment of vague 
fatigue proves to be a good way to go even in patients with dementia, not communicating and / or non-receptive, in which the cause of rejection of the meal can be traced by exclusion to the one in question.

Cause of the I.R.M.I.E. Test $n^{\circ} 04$

THE PATIENT HAS DIFFICULTIES TO PERCEIVE THE APPETITE, IN THE PAST HE DID KEEP SMALL MEALS

The elderly patient who has consolidated in the experience the ritual of eating small meals is particularly vulnerable to malnutrition when, discouraged by the difficulty of consuming the full flow, it develops inappetence and rejection of food. It is recommended to respect his habits, encouraging nutrition with a naturalistic approach through the "Buffet Strategy", in which a dish is presented with a few but various dishes several times during the day, choosing the food that most pleases in a diet specifically designed to be caloric even through the use of supplements as ingredients / seasoning. The moment of meal and hydration can be made more pleasant through the use of a tea room, kiosk and parties as fun and hedonistic moments; also activities have been shown to be effective in which the patient prepares and manipulates food, and the involvement of the family in supporting these "passe-partout" compensations. In the event that there is an important dementia that makes these procedures ineffective, it is possible to stimulate the imitation of the gesture of bringing the bolus to the mouth (with the same special diet) eating together with the patient, with the aim of activating the mirror neurons.

Cause of the I.R.M.I.E. Test $n^{\circ} 05$

THE PATIENT DOES NOT ACCEPT THE STRUCTURE AND HIS INSTITUTIONAL CONDITION

The elderly patient, when he develops awareness of changes in his body and the reduction of his performance, may not accept the condition of assistance and, if necessary, of institutionalization. It follows the loss of self-esteem and mortification, which can manifest itself in anger and aggression or with the onset of a depressive state. In both cases, the will to not feed is a frequent behavior, attributable respectively to a form of protest, resistance to help or abandonment of the self. Of particular importance is the pre-entry home visit and the accompaniment in the structure, moments in which part of the professionals guided by the social worker explain the advantages of life in a retirement home to stimulate interest and concretization. Once accepted, it is a good idea to approach the patient with gentlecare and validation, in order to apply an environmental and naturalistic restraint that makes him feel understood, next to a 
treatment (if any) pharmacological and an acceptance training of the new setting coordinated by the psychology service. The specific intervention to lead to the interruption of the fast, this premised, may consist in making the patient choose at first when, where and what to eat, within the limits of the granted; it is also possible to undertake a conting ent occupational therapy to the problem, electing the elderly to a rewarding and inherent role, for example as a "taster" of the dishes. Visible external visits are often welcomed, in congenial gastronomic settings in agreement with the family, which can spur us to nourish and accentuate the collaboration with the structure team, verified that this does not risk to cause opposition in the return in it.

Cause of the I.R.M.I.E. Test $n^{\circ} 06$

THE PATIENT HAS CONFIDENCE TO THE OPERAT OR (ABOVE ALL IF THE ELDER PRESENTS IPOVISUS)

Due to causes attributable to experience or cog nitive impairment, the institutionalized elderly person can refuse the meal due to distrust of the operator, who moves away. In these cases it is advisable to maintain a gentle and conscious approach to the rules related to the delicacy of the care, involving the family members in the administration and proposing tactile relaxation activities to build trust between the service staff and the patient. If he persists in rejecting a particular individual, he must be indulged when the cause can not be explained.

Cause of the I.R.M.I.E. Test $n^{\circ} 07$

THE PATIENT REFUSES FOOD AS A REFLECTION OF DISAPPROVATIONS FROM THE CARE-GIVERS

In the elderly who maintains (completely or partially) memory and understanding, behavior can be easily conditioned by a caregiver who is not part of the residential community (eg family) in which he has particular trust. If the latter external, consciously or not, mistrust towards the structure (and in particular towards the proposed food), in the patient a refusal to feed itself can be manifested as an event reflected in the perceived skepticism. To overcome the problem, the team's objective will be to establish a synergistic relationship of collaboration with the opposing care-giver, through informative counseling of what is being done and its motivation. Accompanying the daily rituals together between the personal and the family, we invite this last not to abandon the feeding at least in the food passe-partout, and not to condition the patient with his own judg ment, in favor of silence during the execution of the task and other verbal exchanges. In cases where he obstinately puts the danger, the patient must be removed, with the disadvantage of losing the figure towards which the elderly place greater trust at 
that moment.

Cause of the I.R.M.I.E. Test $n^{\circ} 08$

THE MEAL TIME IS INSUFFICIENT WITH RESPECT TO THE NEEDS

The scarcity of meal times can be a cause of inappetence in the elderly, which if it demonstrates awareness of the decay of their abilities can mortify themselves and manifest the refusal to feed themselves. The times necessary for complete consumption of the meal must be respected even in cases where they can vary and become dilated. It is advisable to undertake a well-structured interdisciplinary procedure, which foresees an increase in the time available for the patient to conclude the meal (kept warmed up) and the assignment of aids facilitating autonomy, planning a 1:1 ratio that may also involve family members and invite to caloric additions. The physiotherapy and logopedic rehabilitative treatment will follow the choice of a congruous and nutritious diet, which respects both the easier consistency to be assumed in the slowed patient and the hedonism (in pleasantness and proposal of satisfying tastes)

Cause of the I.R.M.I.E. Test n ${ }^{\circ} 09$

THE PATIENT REFERS TO PERCEIVE ODOR AND / OR TO HAVE A DECREASING VISION DURING THE MEAL

Unpleasant stimuli perceived in the place where the meal is consumed can be the cause of rejection. The institutionalized elder can incur, in the community life, visions, odors and / or annoying noises related to the other guests or the quality of the environment used as a cafeteria, being disgusted, disturbed and picky.

It is very important to sense the discomfort and to intervene, preventing fasting, especially when the subject is not external due to expressive communication deficits or embarrassment.

A valid strategy resides in the change of the seat at the table or in more important cases in the total variation of the setting, so as to isolate as much as possible the patient from the pollutions that penalize the acceptance and consumption of food.

Cause of the I.R.M.I.E. Test $n^{\circ} 10$

THE DIET IS MONOTONE

A diet that does not stimulate the appetite because it is monotonous can be the cause of rejection of the meal in the institutionalized elderly that maintains memory capacity, encouraging among other things the staple of rest acceptance of the structure and the depression deriving from the loss of their own home and habits consolidated in it. To tackle the problem we recommend the search for foods judged pleasant by the 
patient, through an interview, expanding the menu with food that can be safely provided to other patients and using the family to provide the remaining judged legitimate, in a separate location from other diners and under surveillance. Also the presentation of the dish is useful to make the meal moment perceive as warm, informal and domestic.

Recurring interviews in CAA are used for lucid but deficient patients in the communicative output.

Cause of the I.R.M.I.E. Test $n^{\circ} 11$

PATIENT PRESENTS OLFACT ORY / GUST ATIVE SENSORY DISABILITY: FEEL LESS FLAVORS

The gustatory / olfactory sensory disability can emerge from various causes, and if they can not be resolved immediately, it can lead to rejection of the meal. A way to get the patient back to eat has as its objective the reactivation taste with consequent pleasure towards the dishes: assessed the limits and the needs of the patient, are invited as compensatory measures the maintenance of food initially whole and then crumbled or passe-partout and the choice of food and condiments with a strong taste, simultaneously with a sensory rehabilitative training which consists in discriminating the smell at sight, covering the surface of the tongue with tasty creams and the contemporary use where possible of aerosol with an intensely appetizing bolus in mouth.

Cause of the I.R.M.I.E. Test $n^{\circ} 12$

THE PATIENT PRESENTS FOOD REST RICTIONS FOR: DIABETES, ALLERGIES, DIARREA IN TREAT MENT, DIVERT ICULA

The elderly patient may have dietary limitations related to diseases such as diabetes, obesity, the presence of diverticula, food allergies and intolerances etc. developing rejection of the meal secondary to the malaise resulting from the complications related to them. It is very important not to administer foods that compromise the clinical problems of patients, so as not to incur secondary suffering to the intake of what is prohibited that limits the well-being and the serenity of a correct meal. The elderly can also develop lack of appetite, perceiving the negation of some tasty food.

In light of this it is necessary to build a diet that guarantees the health of the patient and however fulfills its expectation, proposing strategies such as sweetening with products that do not increase glycemia in diabetes and overweight, or deprive the food of waste for the patient who suffers from diverticula. There are also specific products that can be purchased for these types of patients as well as for others affected by food intolerances (for example, lactose or celiac disease). 
Cause of the I.R.M.I.E. Test $n^{\circ} 13$

THE DENTAL PROSTHESIS IS INCONGRUENT OR IS EDENTUAL AND THE CONSISTENCY IS NOT CHEAPABLE

In the elderly the edentulism, partial or total, must be compensated with the dental prosthesis to allow a correct and agile chewing. Although in principle built ad-personam, it must be monitored in compliance over time, since it is frequent that the morphology of the arches (especially for the maxillary bone and in case of weight loss) may change in the patient, making it incongruent. This eventuality may represent a cause for rejection of the meal, easily understood but that requires particular evaluation in patients with communication difficulties. The re-adaptation of the artificial teeth is decisive, and waiting for it we recommend a variation in the consistency of the diet (which does not require chewing, eg creamy) favoring the passe-partout dishes so that the momentary passage is gradual and prevents a possible loss of appetite.

Cause of the I.R.M.I.E. Test $n^{\circ} 14$

THE FLAVOR AND / OR THE CONSISTENCY OF FOOD ARE VARY AND PERCEPED AS DISGUSTIVE

The elderly patient with dysphagia or voracity can refuse the meal if the consistency, varied, is unpleasant. When the naturalistic compensations are not sufficient (aids, posture, temperature and food quality) and the artificial dish becomes obligatory (thickened liquids and creamy foods) it is necessary to resort to strategies such as the choice of a diet composed of passe-partout courses and condensation of tasty drinks, granting exceptions in an individual relationship if in safety and carrying out a rehabilitation procedure of speech and acceptance.

A meal of consistency similar to the pudding was recently invented, easily assimilated and suitable for practically any type of dysphagia, which simulates the real image of the nonartificial dish. This innovation is an excellent solution in case of rehabilitative impossibility, of inference of dementia that give the chance to "deceive the eye", as well as in the moments of transition of hypothetical changes of diet.

Cause of the I.R.M.I.E. Test $n^{\circ} 15$

MASTICATION AND DEGLUTATION REQUIRE PHYSICAL EFFORT, BUT THE PATIENT IS PEOPLE AND / OR REDUCED AUTONOMIES

The patient can give up the task of feeding, refusing food, when the act of feeding requires fatigue, that is to say a considerable physical effort in bring ing the bolus to the mouth, chewing and swallowing. It can show discouragement in the awareness of one's own decay, laziness or evaluate the excessively expensive action, sacrificing the pleasure 
of eating. In these cases, in order to interrupt fasting, it is necessary to reacquire confidence and economy to the patient, undertaking a rehabilitative process of the praxis of the upper and oral arts, aimed at increasing autonomy and reducing time and effort during the meal. The food itself can be used as an instrument during treatment, thus increasing the intake of water and heat transversely. The dish presented must have a number of dishes consistent with the conting ent capacity of the patient, who should accept it (mortification must be verified by the psychology service that can also coordinate reality examinations and acceptance interviews) can be supported momentarily with entrance and aids facilitators like cutlery with thick handle or bonneted glasses.

Cause of the I.R.M.I.E. Test $n^{\circ} 16$

THE PATIENT PRESENTS PAIN DURING MASTICATION, DEGLUTING AND / OR

\section{DIGESTION}

The careful and regular follow-up of the status of organs imputed to nutrition must be respected, especially in non-communicating patients, since a cause of rejection of the meal may be linked to pain during chewing, swallowing and digestion. In these cases it is necessary to initiate the clinical and pharmacological resolution of the drugs, choosing in the current diet dishes that do not increase the malaise, that facilitate nutrition (as long as they are not unpleasant), and in some cases that may have analgesic and synergistic qualities to the treatment.

Cause of the I.R.M.I.E. Test $n^{\circ} 17$

THE PATIENT PRESENTS DISTAL PAIN (EXEMPTION FROM INJURY, OT HER SUFFERING ETC.)

The elderly person can refuse food, inappetent, due to the suffering caused by distal pain, such as pressure injuries, org anic and articular suffering, incorrect posture. In these cases, fasting can usually end with the resolution of the pain itself. During health care, it is good practice to try to accept small amounts of food and liquids, which also has a prognostic value of greater therapeutic efficacy. With Gentle-care and Validation approach, we invite the patient to share and legitimize his complaint, to establish a relationship of trust and the awareness of a resolutive perspective. It is necessary to instruct through informative counseling all the figures that interact with the patient (personal, family, care-givers, etc.) on the right methods of handling, feeding and manipulation to prevent the complications of the diseases in progress. As long as fasting and suffering do not decrease, nutrition by mouth should probably be supported in a 1:1 ratio, with particular attention to the treatment of hypothetical dehydration and 
constipation, which are frequent comorbid events in the elderly. In the event that it is not possible to complete the resolution of pain, even in the long term, we invite you to consider a therapy designed to reduce it near meals, such as

Cause of the I.R.M.I.E. Test $n^{\circ} 18$

THE PATIENT IS AFFECT ED BY CHRONICISM OF ORGANIC DISAGARMS (STIPSI, NAUSEA, DIARREA, INFECTIONS ETC.)

In the elderly, inappetence can derive from the chronicity of organic discomforts (constipation, diarrhea, nausea, infections, etc.), which create a ritual or cyclical condition of general malaise, causing the patient not to feel hunger and to refuse food. In these cases it is necessary to resolve the primary cause of pain, through pharmacological treatment or clinical iter planned by the doctor, with parallel interdisciplinary work of the team to find strategies that prevent a new onset of the disease. During this process it is advisable to intervene on the rejection of the meal in individual feeding relationship to integrate the patient (albeit initially in small quantities) at the water and calories level. Regardless of the problems in progress, it is good practice to pay particular attention to the treatment of hypothetical dehydration and constipation, which in the elderly there are frequent comorbid events (eg in cystitis, bladder catheter, emesis, diarrheal discharges, bedsores) . The diet chosen for the patient, while providing in principle "tastings", will be chosen to stimulate consumption, investigating his preferences and the most inviting and tasty dishes, selecting among them the most digestible, caloric and synergistic to the treatment (generally this concerns the inclusion or exclusion in solids and liquid suspensions of proteins, carbohydrates and fibers). In particular, hydration, which is beneficial in all areas, can intervene positively on urination, preventing the imposition of bladder dyes which can in turn be the source of infectious foci; it can also be stimulated with the use of herbal teas and spaces dedicated to the pleasant consumption of liquids such as "Sala da te" and "Chiosco". In cases of stubborn emesis and diarrhea, nutrition should have the characteristic of being nutritious, reinteg rative and at the same time digestible, using dishes that do not increase the malaise, consistencies facilitating nutrition as long as pleasing, use of supplements and food products of homeopathic mold that can have both an energetic and curative function and an analgesic function. Finally constipation can be treated, within the clinical limits of the case, using evacuation teas, oil project, proposal of vegetables, legumes and cereals in abundance, choice of the most suitable fruit and integral models of dishes as an important source of fibers and natural stimulators of peristalsis. 
THE PATIENT PRESENTS A COMPROMISION / COMPROMISE OF ORGANS (ULCERS, METEORISM ETC.)

In the elderly, the refusal of food can be linked to a sense of apparent satiety, linked to crushing, compression and / or impairment of the digestive organs (esophagus, stomach, diaphragm, intestine, etc.). The causes can be inflammation, tissue lesions, meteorism and neoformations (for example, ulcers, air in the bowels, masses ...). Although causing symptoms similar to cases of pain during swallowing / digestion and constriction from constipation or eventual restraint, the circumstances discussed here often provide a more complex solution to the problem, and therefore must be treated differently, in the awareness that nutrition and therapy pharmacology can only reduce the malaise. Therefore, parallel to the clinical procedures, we recommend the administration of selected foods to give relief with respect to the specific disorder and absorption capacity, with the aim of preventing malnutrition and establishing a collaboration that allows the patient's confidence to return to the fasting and unhappy patient. be able to take specific foods that do not accentuate their physical pains, but rather are pleasant, analgesic, easily digestible and preferably caloric.

\section{Cause of the I.R.M.I.E. T est $n^{\circ} 20$}

THE PATIENT HAS SENSATION OF CRUSHING / INCOORDINATION DUE TO CONTENT In the institutionalized elderly, with dementia, physical restraint can cause rejection of the meal for a variety of reasons. In fact, by limiting movement, it can make difficult the act of feeding (when autonomous) making the task excessively complex and bringing the patient to renouncement; physical restraint can distract the elderly from hunger and concentration towards food because they want to remove it (or wonder what it is) and if it creates a compression on the diaphragm and / or on the digestive organs, it can lead to lack of appetite for a false sense of satiety. In these cases, to prevent malnutrition, it is advised to remove the restraint at the time of the meal, provided that the gentleman is however conting ently in safety, replacing the aid with a table or close surveillance.

Cause of the I.R.M.I.E. Test $n^{\circ} 21$

THE PATIENT PRESENTS COMMUNICATIVE DEFICIT (AFASIA, DISHONIA, DISTRUST, HEARING DISABILITY)

The communication-linguistic deficits, whether in input and / or output (aphasia, dementia, dysarthria, dysphonia or weak voice, hearing disability, mutism, etc.) are hardly a direct cause of the refusal of the meal, if not for nervousness and mortification in cases where the elderly person is aware of their handicap. However, they represent an obstacle to the investigation of the primary cause of the 
refusal, which it is good to know how to deal with to interpret the needs of the patient. When a patient refuses the meal for reasons unrecognizable due to a severe deficit both in production and in non-rehabilitative comprehension (eg serious pictures of global aphasia or dementia), we invite to provide extremely simple forms of CAA to enter into a relationship, after a cognitive therapy training in the psycho-linguistic-environmental field. The same can be applied in the Aug mentative Alternative Communication, next to the speech therapy rehabilitation, in cases in which the refusal of the meal appears in non communicating receptive patients (eg motor aphasia, deaf-mutism, dysarthria and dysphonia).

On the other hand, when a patient refuses the meal for unrecognizable reasons and his speech, intelligible, is apragmatic (eg, Frontal, Fronto-temporal and Alzheimer dementia, Sensory Aphorias), it may be useful to note the most frequent lexicons of the confabulations so to start the interpretation of his explanation of the problem from a point more plausibly close to what he is trying to expose.

Cause of the I.R.M.I.E. Test $n^{\circ} 22$

HYPOT HET ICAL SIDE EFFECTS OF PHARMACOLOGICAL THERAPY (ES ASSAYMENT) In the elderly patient, drug therapy can have multiple side effects, given by the single principle / component but also by the mutual interaction of different drugs. Among the most dangerous consequences that may appear attention is paid on the possible inability to feed due to fatigue or drowsiness, even giving up the task, or provoking a refusal related to decompensation on the cognitive level (eg hallucinations, depression). To prevent fasting, which only apparently results in a renunciation of food, it is necessary to evaluate the interruption of the therapy by verifying the actual presence of a sudden decay or not, and proposing an alternative plan. The periods of low performance must be followed with individual interventions to administer an artificial diet, integrated to guarantee a caloric and protein intake as correct as possible, making swallowing safe and stressed with logopedic therapy (likely passive) of glottal electrostimulation and facilitating postures. Synergistic to this is a study work of strictly environmental restraint that goes in itself to reduce the patient's behaviors that have made therapy necessary, experimenting with different interventions until the most effective ones are identified.

Cause of the I.R.M.I.E. Test $n^{\circ} 23$

THE PATIENT IS SUBJECT TO LOW ARTERIAL PRESSURE LINKED TO THE RAISING OR PARISISTIC POSITIONAL VERTIGATION

In the elderly, an apparent refusal of the meal due to reduced vigilance / malaise / dyskinesia can be caused by vertigo related to postural passages, be it paroxysmal 
positional or secondary to low pressure at the time of the lift. In these cases it is advisable to administer the meal away from the change of posture, respecting the "refractory" moment in which the patient could suffer from a discomfort linked to it, and fasting for soporosity, agitation or disorientation.

Cause of the I.R.M.I.E. Test $n^{\circ} 24$

PATIENT PRESENTS ORIENTATION DISORDERS RELATED TO CHANGE AND ENVIRONMENT, LOSSES AND COMBINES IN SPACE, DOES NOT RECOGNIZE NEW DOMESTIC SETTING

The elder with cognitive decay can disorientate into space once institutionalized, losing or seeking the domestic environment. Uncomfortable and agitated due to the new unrecognized setting can be followed by episodes of rejection of the meal, which if frequent make the patient in danger of malnutrition. In these cases it is advisable to repeat the food at different times, when rejected due to disorientation, and the involvement of one or more people who have lived with the gentleman (eg family members) to make him feel "at home" and reassured. It is important to use a small room that is poor in distractions, since the small space is better org anized and explored by the patient. Also what is proposed during the meal (dish, cutlery, dish, etc.) must be as reminiscent as possible of its experience, so as to have food-related elements available that "bring it back" to a family setting.

Cause of the I.R.M.I.E. Test $n^{\circ} 25$

THE PATIENT PRESENTS SEVERAL DISORDERS OF TEMPORAL ORIENTATION AND REFUSAL TO SUPPLY FOOD TO HYPOT HETIC CHILDREN, EVEN SMALL, COMBINES THE DOLL THERAPY DOLL FOR THEM

The elderly person with serious disorders of temporal orientation (for example due to dementia) can refuse food to provide it to figures identified in small children who want to take care of it, be they hallucinations or objects, such as Doll of Doll Therapy. In these cases it is necessary to reduce the decompensing factors present in the environment that can cause this behavior and remove the object at meal time, enjoying the rest of the day the benefits it can give, if the patient does not maintain a memory to oppose. It is however permissible, with a validation approach, to support the elderly to eat the meal together with the fetish, perhaps proposing a bottle, and to involve the family members to stimulate him to concentrate on other activities of reminiscence. 
Dementia can lead to the loss of the recognition of food as such and of the act of eating, causing a stubborn refusal to eat. To overcome the problem, it is necessary to conduct the patient in a non-polluted setting, free from any disturbance, where one food at a time is proposed as the sole source of attention. The patient is allowed to play with food, taking his confidence to explore it with his mouth and taste it. Afterwards, the task is maintained through activation of mirror neurons by imitation of the gesture, with foods prodding the oral mucosa and, if it accepts and does not distract, glottal electrostimulation. Given the re-emergence of the infant's behavior, hydration can be proposed in the bottle to stimulate suction, in setting Snoezelen (neurostimulant).

Cause of the I.R.M.I.E. Test $n^{\circ} 27$

THE PATIENT FORGETS THE BOLO IN THE MOUTH DUE TO THE DEMENCE

When the elder with dementia "holds the morsel" we can think of a short-term memory deficit if no cough, bavage or empty swallowing appears. The disorder of MBT leads to forget the bolus in the mouth even immediately after receiving it, implying an apparent refusal with rejection or passivity, case in which increasing the risk of penetration of the same in the airways are forced maneuvers for its removal. With the aim of preventing malnutrition, it is recommended to provide dishes at low temperature and carbonated liquids, which unlike most traditional courses are inevitably recognized as edible foreign bodies in contact with the oral tissues and induce motility. It is good practice to plan a training that precedes and accompanies the meal to urge the swallowing and the cable praxis, through stimulation with thermal stresses, TENS glottica and the use of facilitating aids.

Cause of the I.R.M.I.E. Test $n^{\circ} 28$

THE PATIENT PRESENTS ALLUCINAZIONI THAT DIST URBANO (PERSECUTION, HEAR BODIES IN THE MOUTH ETC.)

The elderly with dementia can refuse the meal due to hallucinations that disturb him, making him believe for example that the food is poisoned or has foreign bodies in the mouth. To solve the problem in these cases, some strategies have proved to be effective, including preparing the meal with the gentleman in order to create a situation that does not allow food manipulation by third parties and acts as a "test" to reassure the goodness and harmlessness of the food to be taken. If it is necessary to use a supplement, it is possible to supply it as a mouthwash to be swallowed during oral hygiene. It is good practice to elect a figure to whom the patient puts unconditional trust (a family member, the parish priest who comes to Mass etc.), to be placed side by side in the act of nutrition. 
Cause of the I.R.M.I.E. Test $n^{\circ} 29$

PATIENT PRESENTS PUERILE REGRESSION: REFUSED FOR DISPATCH OR AS A CHILD SCHEME

The elderly person with severe cognitive impairment may show observable behaviors in the newborn, including the refusal of food as a child's pattern (for example, of spite and rejection towards the entrance). In these cases it is advisable to approach the problem as if it were placed in a small child, allowing the patient to manipulate the food independently. To support this search for independence in the act of feeding, it is advisable to provide cutlery that facilitates the task and be aware that the detached surveillance of the gentleman will result in a greater welfare load related to hygiene after the meal, since it is possible that it gets dirty. The most favorable environment to prevent disturbances must be poor in noise, pollution and distractions (recommended for example their room), proceeding in the administration of dishes with Gentle-care approach and encouraging relaxation and collaboration through tactile contact and, if the accept, the Doll Therapy. The sweet dishes are often privileged: they are preferred and sweetened with specific products in case of diabetes. If the reflex of the suction without dysphagia re-emerges, it should be exploited above all in the hydration, using, depending on the case, a bottle, a straw or a beaker.

Cause of the I.R.M.I.E. Test $n^{\circ} 30$

THE PATIENT PRESENTS STIMULATE CONSTANT TO GO IN THE BATH BUT DOES NOT HAVE THE AUTONOMY TO DO IT

The elderly person can renounce the meal, refusing it, to placate a constant sensation of imminent evacuation or urination, either real or apparent, causing inappetence and agitation. The lack of autonomy in the act or the repeated repetition (until it becomes practically constant) of the unsatisfactory stimulus can lead the patient to want to move into the toilet during all the time dedicated to nutrition, which will be sacrificed.

To stop the fast and prevent malnutrition, it is necessary to look for the cause, physical or pathological, that leads to the discomfort, taking care of it. If this is not possible, it is right to propose a support measure chosen by the doctor according to the case (eg pelvic absorbent cloth) and to introduce the acceptance of the same through cognitivebehavioral training.

If even this is not possible (usually due to marked cognitive impairment) it is advisable to have the patient eat near the services in the compromise to accompany them from time to time at the end of the single course or, in cases of resistance with autonomy or individual relationship, it is possible to consume the meal by placing the patient on the 
toilet, where he could find more relief and safety.

Cause of the I.R.M.I.E. Test $n^{\circ} 31$

THE PATIENT PRESENTS WANDERING, HAS DIFFICULTIES TO REMAIN STILL DURING THE MEAL

"Wandering " refers to a behavioral symptom that may appear in subjects affected by dementia and is manifested in the need to perpetrate a continuous, non-causal and afinalistic movement; for those who are affected, this need is perceived as being of primary importance with respect to hunger and thirst, making it difficult to maintain the static and concentration required to take the meal, which can be refused. To overcome the problem, it is advisable not to force the patient to maintain a static position, making him choose to stop and where; if it does not want to, it is necessary to accompany the patient during his perpetual walk with the plate and the glass, so that he eats and drinks walking, and the same thing must be done in the wheelchair in motion if it does not move. In general, it is advisable to propose a single dish, with a neurostimolating color that has the capacity in small portions, so that the sensation is that of being able to satisfy the sense of hunger by sacrificing the minimum time to wander; the meal should be offered several times a day when it refuses it, offering various "snacks" as frequently as possible and choosing the most pleasant dishes from the patient to stimulate consumption. Besides these precautions, the activation of the Mirror Neurons by imitation is optimal if the gesture of bringing food to the mouth is not spontaneous, and above all the construction of a space inspired by the "Snoezelen Room", ie a structured setting in environmental components designed to create attention focus and attractive suggestions with sensory stimuli, which aim to transfer / satisfy in them the "wandering movement" (for example, the projection of audio-visual sequences such as the fireplace fire, the aquarium with fish, a cylinder of bubbles or a conical spiral and the simulation of a train car in motion) and to create moments of concentration.

Cause of the I.R.M.I.E. Test $n^{\circ} 32$

THE PATIENT PRESENTSFAULT OF SUFFOCATION AFT ER A NEGATIVE REINFORCEMENT EPISODE

An episode of suffocation can sometimes be experienced by the elderly as a shock, creating a fear that refuses food because of the fear that the event may repeat itself, with the consequent risk of malnutrition. The interdisciplinary intervention of the team will have the objective of reacquiring safety to the patient of his ability to swallow in a safe and repeatable way. The path, generally coordinated by the psychology service, begins with the research of the patient's collaboration, which will have to accept the first external 
contact of the oral cavity, for example through hygiene. We can continue, with a view to a "Validation" approach (which validates and legitimates the behavior of the patient through empathy) with the attempt to facilitate and cautious feeding, explaining the effectiveness of the precautions taken. In this cognitive-behavioral psychotherapy, an examination of reality that can lead to reflection on the consequences of fasting and incentives to face the phobia may be useful. As a positive reinforcement, the resumption of feeding is allowed in frequent and continuous rehabilitation training for dysphagia, to monitor and treat all the phases of meal consumption and ensure qualitative and quantitative safety. This disorder is most noticeable in the polished elderly or with mild dementia, as in cases of more severe cognitive impairment, memory may not be retained in memory.

Cause of the I.R.M.I.E. Test $n^{\circ} 33$

THE PATIENT HAS SADNESS FOR THE LOSS OF THE HOUSE AND VARYES RIT MI AND HABITS CONSOLIDATED IN IT

The institutionalized elderly person can refuse food due to lack of appetite deriving from the sadness of the loss of the home and due to the sudden variation of the rhythms and eating habits consolidated in life. In these cases, a gradual change in meal times is proving useful, temporarily allowing to consume liquids and dishes according to one's own rituals, choosing among the ones that appear most familiar for quality, consistency and preparation, and presenting a space dedicated to itself . In case of diagnosed depression and if foreseen by the doctor, it is possible to undertake a pharmacological therapy. Regardless of this, it is necessary to establish a new and pleasant daily life in the patient, involving him in structured occupational activities (if possible concerning food, as culinary laboratories or the care of the garden). In these activities, the involvement of the family is desirable in order to make the institute a new setting that is recognizable and not deprived of affections. The same can be active members in external visits that involve the consumption of a meal (eg at the bar, refreshments in exhibitions and, if not decompensating, in the house itself). It is possible to accentuate the link with the outside, the loss of which is in this case a source of sadness, even with "correspondence projects" in which the patient calls or writes to the acquaintances, if you find comfort.

Cause of the I.R.M.I.E. Test $n^{\circ} 34$

THE PATIENT HAS LOST AUT OSTIMA: IT IS MORTIFIED IN THE ENDLESS BEING AND IN THE LOSS OF THE AUTONOMOUS

The elderly person can refuse food when he / she eats the meal as a source of mortification and humiliation, in being fed or in showing poor autonomy. 
In these cases, to stop the fast, it is necessary to reacquire the patient self-confidence, undertaking a rehabilitative physiotherapy process of the praxies of the upper and oral arts, aimed at increasing self-management judged to be dignified, and involving the psychology service for stimulate acceptance of your condition. The food itself can be used as an instrument during treatment, thus increasing the intake of water and heat transversely. The dish presented must have a quantity of food coherent with the patient's conting ent capacity, which, if accepted, can be temporarily supported with facilitating aids such as a thick handle cutlery or cuffed glasses. If you do not appreciate a result and there was no other solution than the entrance, it can be done by personnel or caregivers (eg family members) with whom it has established a relationship of esteem and collaboration, granting the help ; careful assessment of seeting is advised, generally closed to prevent the elderly person feeling judged, re-evaluating if this becomes a source of isolation and negative reinforcement.

Cause of the I.R.M.I.E. Test $n^{\circ} 35$

DEPRESSION AND STRESSING EVENTS WITH THE BEHAVIOR OF APATIA TOWARDS FOOD

The refusal of food in the elderly may be a symptom of the Anedonia of depression, that is, the loss and inability to feel pleasure in any activity, including circumstances and actions normally pleasing, such as feeding oneself.

The problem in sufficiently lucid patients can be addressed by the arrangement (establishment or variation) of an antidepressant drug therapy by the doctor, combined with psychotherapy conducted by the psychology service. The latter, generally cog nitivebehavioral, can follow the adaptations illustrated in the scientific literature of psychogeriatria for example with the approach of Karasu (1997, argued by Marangoni \& Lodi, 2015), seizing the psychodynamic criterion (described by Adriano Legacci , 2014) and some specific therapeutic indications for the treatment of depression in a psychoanalytic perspective (Mc Williams, 1994).

To this may be associated a tactile stimulation, sensory and affective, which includes contacts, relaxing massages and caresses designed to pursue the well-being of the patient, encouraging a sense of reassurance. The search for a goal to be pursued and a rewarding role at the employment level, such as feeding and manual activities, proved to be very useful. Finally, it is possible to find pleasing and evocative foods for the patient, which he can help to prepare, involved in a cooking laboratory.

The whole is applicable when no signs of psychogenic esophageal dysphagia appear, often frequent evolution.

On the other hand, in the elderly with dementia, the pharmacological therapy of an 
antidepressant, antipsychotic or anxiolytic form can be associated with the same occupational, culinary activities and the proposal of pleasing and evocative dishes, finalizing the objective of reactivating the function of food; in fact, if the cognitive impairment is serious, the deficit in the memory and in the linguistic understanding does not allow the psychotherapeutic treatment with the same guarantee of effectiveness with respect to the lucid patient. Tactile sensory stimulation, on the other hand, can be enriched with the construction of the Snoezelen setting, which, besides having the function of reassuring the patient with decay, can "distract" him from the depressive state, temporarily focusing his attention on the sensory chamber elements.

Cause of the I.R.M.I.E. Test $n^{\circ} 36$

THE PATIENT CHOOSES TO "REFUSE LIFE", WANTS TO ACCELERATE THE DEPARTMENT

The refusal of food in the polished elderly can be a conscious choice of repudiation to life, with the goal of accelerating death. This problem must be approached similarly to the rejection of the meal in the depressed patient, regardless of the nature (pathological or otherwise) of the event and of the ethical discussion on the legitimacy of supporting or not a will of this type.

Depending on the choice of doctor, the training to accept the meal can begin with the arrangement (establishment or variation) of an antidepressive drug therapy, combined with psychotherapy conducted by the psychology service. The latter, generally cognitivebehavioral, can follow the adaptations illustrated in the scientific literature of psychogeriatria for example with the approach of Karasu (1997, argued by Marangoni \& Lodi, 2015), seizing the psychodynamic criterion (described by Adriano Legacci, 2014) and some specific therapeutic indications for the treatment of depression in a psychoanalytic perspective (Mc Williams, 1994).

This path may include: examination of reality, promotion of the maintenance of vigilance in the context of the emergence of destructive impulses, dissuasion from undertaking great changes based on the contingent emotional state, support of the state of mind, achievement of a more optimistic perspective ( perhaps obtaining the support of other people who are part of the patient's social network), proposing goals that are realistic and achievable (as well as stimulating and suitable for the setting of an institutionalized elderly, such as the manual creation of small gifts for visitors), encourag ement to look for new experiences of success (always contextualized, such as the delivery of the gift itself, self-built) and finally the reduction of the patient's symptoms, causing him to recognize the self-destructive thoughts.

If the meal is partially accepted, it is important to supplement the intake with high-calorie 
products to make it sufficiently nutritious. To this may be associated a tactile stimulation, sensory and affective, which includes contacts, relaxing massages and caresses designed to pursue the well-being of the patient, encouraging a sense of reassurance. The search for a goal to be pursued and a rewarding role at the employment level, already mentioned, turned out to be very useful. Finally, it is possible to find pleasing and evocative foods for the patient, which he can help to prepare, involved in a cooking laboratory.

The whole is applicable when no signs of psychogenic esophageal dysphagia appear, often frequent evolution.

This type of process is suggested for lucid people, because in the elderly with dementia, on the contrary, it is very difficult to interpret a certain rejection of the meal as a voluntary denial of life (suicide) due to communication and memory deficits. and understanding.

\section{Cause of the I.R.M.I.E. Test $n^{\circ} 37$}

THERE IS A PREGRANT OR CURRENT ANORESSIA AND / OR PSYCHIAT RIC DISEASE In some cases the polished elder can refuse the meal due to a disturbance of his body image, fearing to gain weight and to make himself more "imperfect". In the absence of dementia or other cog nitive decays, this behavior is due to psychiatric / affective disorders or anorexia nervosa, sometimes present in the patient's history. In these cases, similarly to eating disorders, it is possible to treat fasting with pharmacological therapy and psychotherapy (cog nitive-behavioral and dynamic), which will focus on the acquisition, processing and acceptance of one's body scheme and the replacement of food rejection with acquisition of a reduced (but sufficient) diet.

To make the meal initially accepted, counseling aimed directly at the patient is also useful, explaining and demonstrating the importance of the fluids to maintain the state of health and the impossibility of gaining weight following a balanced diet.

Cause of the I.R.M.I.E. Test $n^{\circ} 38$

THE PATIENT PRESENTS ASTINENCE FROM DRUG OR PREGRANT DEPENDENCY FROM PSYCHOTROPE SUBSTANCES AND ALCOHOL

Elder who has a history of addictions and abuse of psychotropic substances may refuse the meal as a nervous manifestation of abstinence, reduction of a given chemical component foreign to the organism or provocative temperament. Next to a psychotherapeutic process, detoxification and / or pharmacological therapy (if provided by the doctor) it is possible to approach the patient with the goal that he goes back to accepting liquids and food through "placebo effect", that is proposing similar dishes and 
drinks in shape, vision and taste to what it requires (eg tasty non-alcoholic wine or fresh red tea).

Cause of the I.R.M.I.E. Test $n^{\circ} 39$

THE PATIENT IS AFFECTED BY "NODE IN THROAT" OR VOMITING FOR ESPHAGEAUS DEFESSION (AND DEPRESSION OR ANSIOGENO STATE UNCONSCIOUS) OF TYPE PSYCHOGEN

The elderly person can refuse the meal due to a sensation of "lump in throat" and nausea, symptoms that, in the absence of infectious, obstructive-morphological, mechanical-motor or neurological / neuromuscular causes, can be traced back to a Psychogenic type of Esophageal Dysphagia., in which an unconscious anxiety-producing state seems to re-emerge.

In an attempt to resolve the disorder and prevent malnutrition, it is necessary to set up an antidepressive or antipsychotic drug therapy as appropriate, and to investigate any disruptive factors present in the environment to be adapted to the patient, associating a relaxation and reassurance training to it. which can start from gentle body contact. In the sufficiently lucid and collaborating patient the psychotherapeutic treatment is invited, while in the subject with more pronounced cognitive deterioration it is necessary to administer the meal in a Snoezeln Chamber, conceived with elements able to capture the attention of the gentleman and distract him from his anguish, reducing it. At food level, as the difficulty of the esophageal passage of the bolus and vomit is reduced, a specific diet must be identified that guarantees sufficient water and calories in the moments when feeding is possible. Parenteral Artificial Nutrition will be valid to compensate for fasting before any benefits of interdisciplinary treatment (eg CVC, Midline, infusion for drip), while the long-term efficacy prognosis (eg PEG) may be affected by vomiting, if not reduced, would lead to rejecting what was introduced.

Cause of the I.R.M.I.E. Test $n^{\circ} 40$

THE PATIENT IS A BEARER OF PEG / SNG BUT CAN NOT ASSUME HOW IT IS INTRODUCED IN THE STOMACH

Enteral Nutrition may not be, to varying degrees, absorbed by the stomach, generally due to the function of the medium or organ. In cases where it appears emesis without an apparent reason (pathologies of the digestive or nervous apparatus, alteration of metabolites / electrolytes, infections or side effects of drugs) it is possible to suppose a rejection of psychogenic nature in which, like the esophageal dysphagia unexplained, an unconscious anxiety-producing state appears to re-emerge. Similarly to this, in an attempt to resolve the disorder and prevent malnutrition, it is 
necessary to set up an antidepressive or antipsychotic drug therapy as appropriate, and to investigate any disruptive factors present in the environment to be adapted to the patient, associating it with a training of relaxation and reassurance that can start from gentle body contact.

In the sufficiently lucid and collaborating patient the psychotherapeutic treatment is invited, while in the subject with more pronounced cognitive deterioration the activation of the Artificial Nutrition medium in a Snoezeln Chamber is necessary, conceived with elements able to capture the attention of the gentleman and distract him from the own anguish, reducing it.

In both cases, the most advantageous strategy turned out to be enteral infusion during moments of deep sleep that alternate with wakefulness, in a cyclicity guaranteed by therapy.

\section{References}

1. ^ http://www.salute.gov.it/portale/documentazione/p6 22 1.jsp? lingua=italiano\&id=1435

2. `Matthias Pirlich, Tatjana Schütz, Martin Kemps, Niklas Luhman, Natalie Minko, Heinrich Josef Lübke. (2005). Social risk factors for hospital malnutrition. Nutrition, vol. $21(3), 295-300$.

3. ${ }^{\wedge}$ http://www.epicentro.iss.it/problemi/mortalita/cert-morti.asp

4. ^ http://www.valoreinrsa.it

5. ^ http://www.valoreinrsa.it/strumenti-di-lavoro/malnutrizione.htm/

6. ^ Lucio Lucchin, PIMAl group, Amleto D'Amicis, Maria Gabriella Gentile, Nino Carlo Battistini, Maria Antonia Fusco. (2009). A nationally representative survey of hospital malnutrition: the Italian PIMAI (Project: Iatrogenic MAlnutrition in Italy) study. Mediterr JNutr Metab, vol. 2 (3), 171-179.

7. ^ M ELIA, L ZELLIPOUR, R STRATTON. (2005). To screen or not to screen for adult malnutrition?. Clinical Nutrition, vol. 24 (6), 867-884.

8. ^ http://www.salute.gov.it/portale/documentazione/p6 2 2 2 1.jsp? lingua=italiano\&id $=1435$

9. ${ }^{\wedge}$ https://www.sigg.it/assets/congressi/52-congresso-nazionalesigg/slide/nursing/12Coin.pdf

10. ^ M Suominen, S Muurinen, P Routasalo, H Soini, I Suur-Uski, A Peiponen. (2005). Malnutrition and associated factors among aged residents in all nursing homes in Helsinki. EurJ Clin Nutr, vol. 59 (4), 578-583.

11. 
http://www.as/brescia.it/media/documenti/anziani/pagina\%203090\%20protocolli\%20R SA\%20RSD dicembre\%202015/01\%20-\%20Alimentazione.pdf

12. ^ https://www.amazon.com/refusal-food-elderly-patient-

Identification/dp/1717832849 